\title{
Introduction to the Minitrack on Digitalization of Work
}

\author{
Tobias M. Scholz \\ University of Siegen \\ tobias.scholz@uni- \\ siegen.de
}

\author{
Juho Hamari \\ Tampere University \\ juho.hamari@tuni.fi
}

\author{
Maria Törhönen \\ Tampere University \\ maria.torhonen@tuni.fi
}

\author{
Brian McCauley \\ Jönköping University \\ brian.mccauley@ju.se
}

\section{Introduction}

The ongoing digitalization of our lives has revolutionized the working world [1]. Concepts that include digital labor and playbour, the gig economy, the platform economy, the sharing economy, crowdsourcing, algorithmic automation, cloud-working, liquid workforce, esports, people analytics, the blockchain, human automation resource management, and Industry 4.0, have developed new digital professions and working conditions. They have led to an intensification of work-life-blending. At the same time, the recent changes to our traditional working environments (i.e., COVID lockdowns) have accelerated the need to extend and develop our digital approaches to working environments and our work-life balance. Thus, we are experiencing a paradigm shift in our workforce and working environments, which poses great opportunities and threats for existing and future forms of digitized work. This paradigm shift requires more significant, innovative, and multidisciplinary research to address the current issues we are experiencing during the transition phase to a (hopefully) Post-COVID world and ways in which modern digital professions can guide the transition of our traditional work environments. Thus, it becomes evident that the working world has changed immensely in the last years and will continue to change in the coming years fundamentally. "Analog" work forms will become more obsolete, and hybrid work forms will become the "new norm."

COVID-19 can be seen as an enforced and accelerated paradigm shift that challenges the way we work during the crisis and the Post-COVID working world [2]. While there is existing research on, e.g., virtual teams, international communication, and many other digital-enhanced collaborations, there is only limited knowledge on the long-term effects of such a shift [3]. However, there is already research emerging, focusing on the dark sides of this new normal; well- being and mental health [4], distant leadership [5], surveillance and trust [6], communication [7], or the zoom-fatigue [8]. Despite many propagating that digital work is unavoidable, that work will be "in the cloud" [9], the lockdown reveals that some form of hybridization is necessary. Therefore, it will be essential to research existing work forms that bridge the digital with the analog world, e.g., esports, open-source development, and remote work. There is a call in the human resource community to use this shift and apply bold and critical research [10].

\section{Topics in the Minitrack}

This can be observed in this minitrack, which has its premiere in the HICSS-55. The call for papers led to 12 submissions in which the chairs selected six papers for presentation. The papers range from HR practices, privacy and transparency, digital nomads to how learning evolves. In that, a wide range of topics concerning the digitalization of work is covered.

The current pandemic highlighted the difficulty of balancing privacy and transparency in a digital workplace. Maren Gierlich-Joas, Mena Teebken and Thomas Hess address this topic in their paper "A Synthesized Perspective on Privacy and Transparency in the Digital Workplace." In that paper, the authors discuss the privacy-transparency-paradox that is underresearched and under-discussed in the digital workplace. They are highlighting the relevance for understanding that privacy and transparency are interconnected. Therefore, digital work has to address the way how to balance trust and surveillance.

That the working world is changing is shown in the paper "Digital Nomad Entrepreneurship and Lifestyle Design: A Process Theory" by T. S. Stumpf, Christopher Califf and Jaime Lancaster. Here, the authors shed light on new work phenomena that emerged out of the digitalization of work. With the flexibility of the workplace, it becomes evident that entrepreneurship may change in the sense of its lifestyle or its business/technology use. Focusing on the digital 
nomad, the authors show a discrepancy in existing research, with their work demonstrating that lifestyle and business/technology use are inherently connected.

The paper "How Well Did I Do? The Effect of Feedback on Affective Commitment in the Context of Microwork" of Anna-Maria Staiger, Johannes Schmidt and Dietrich von der Oelsnitz also focuses on a work form that emerged through the digitalization of work. Crowdworking has gained popularity in recent years with the sales pitch that freelancers for anything are available, but without answering the question, how committed are they? The authors use feedback as a way to influence affective commitment. The results show that investing in a social relationship, even in crowdwork, positively impacts performance. Thus, even in the digital workplace, feedback and social interaction are extremely important.

The digitalization of work also creates new needs from employees as well as new ways to recruit employees. In their paper "Dissection of AI Job Advertisements: A Text Mining-based Analysis of Employee Skills in the Disciplines Computer Vision and Natural Language Processing," the authors Henrik Kortum, Jonas Rebstadt and Oliver Thomas researched the skills in job-postings for computer vision $(\mathrm{CV})$ and natural language processing (NLP) are requested by the job market. CV and NLP are major fields in artificial intelligence, so the job market is highly contested. Consequently, there is a need for specific job skills descriptions based on a company's needs as there is no standard profile for an AI expert.

In the next paper on "Stickiness Impediments in Digital HRM," the authors Rennie Naidoo and Sifiso Ndlovu focus on the struggle to digitalize Human Resource Management. Thereby, they propose that the reason for the inertia to adapt is the stickiness towards existing and traditional routines. This approach emphasizes the struggle for organizations to achieve digitalization in the workplace, even if the change is widely accepted. The authors help to explain the digitalization inertia at workplaces and the need to find specific solutions for the context in the organization.

Finally, digital work also led to a shift in the way learning is perceived and done. The authors Julian Decius, Timo Kortsch, Hilko Paulsen and Anja Schmitz developed a framework on learning in their paper "Learning What you Really, Really Want: Towards a Conceptual Framework of New Learning in the Digital Work Environment." This study highlights that there is a human-centered approach in the digital work environment, but employees need to see the benefit of learning. Therefore, it is important to not only focus on learner autonomy but, more importantly, on learner enthusiasm.
All papers show that digital work requires a unique understanding of the digital work environment and that existing solutions must be evaluated.

\section{Conclusion}

The digitalization of work will increase in the future. Even more, the current pandemic showed that it is possible to create a digital workplace. However, the massive increase in mental health issues also indicates that we need to find balance and create a hybrid workplace. Therefore, more research is necessary to utilize the benefits like flexibility and counter-act challenges like social isolation. Thus, the topic will stay prevalent in the near and extended future with value for both theory building and identifying practical solutions

\section{References}

[1] Kniffin, K. M., Narayanan, J., Anseel, F., Antonakis, J., Ashford, S. P., Bakker, A. B., and Vugt, M. V., "COVID19 and the Workplace: Implications, Issues, and Insights for Future Research and Action," American Psychologist, 76(1), 2021, pp. 63-77.

[2] Brammer, S., Branicki, L., \& Linnenluecke, M. K., "COVID-19, Societalization, and the Future of Business in Society," Academy of Management Perspectives, 34(4), 2020, pp. 493-507.

[3] Budhwar, P., and Cumming, D., "New Directions in Management Research and Communication: Lessons from the COVID-19 Pandemic," British Journal of Management, 31(3), 2020, p. 441.

[4] Carnevale, J. B., and Hatak, I., "Employee Adjustment and Well-being in the Era of COVID-19: Implications for Human Resource Management," Journal of Business Research, 116, 2020, pp. 183-187.

[5] Tourish, D., "Introduction to the Special Issue: Why the Coronavirus Crisis is also a Crisis of Leadership," Leadership, 16(3), 2020, pp. 261-272.

[6] Blumenfeld, S., Anderson, G., and Hooper, V., "Covid19 and Employee Surveillance," New Zealand Journal of Employment Relations, 45(2), 2020, pp. 33-41.

[7] Sanders, K., Nguyen, P. T., Bouckenooghe, D., Rafferty, A., and Schwarz, G., "Unraveling the What and How of Organizational Communication to Employees During COVID-19 Pandemic: Adopting an Attributional Lens," Journal of Applied Behavioral Science, 56(3), 2020, pp. 289-293.

[8] Richter, A., "Locked-down Digital Work," International Journal of Information Management, 55, 2020, 102157.

[9] Cappelli, P., "Stop Overengineering People Management," Harvard Business Review, 98(5), 2020, pp. 56-63.

[10] Bierema, L. L., "HRD Research and Practice after 'The Great COVID-19 Pause': The Time is Now for Bold, Critical, Research," Human Resource Development International, 23(4), 2020, pp. 347-36 